\title{
Directions and Trends in Industrial Organization: A Review Essay on the Handbook of Industrial Organization
}

THE HANDBOOK OF INDUSTRIAL ORGANIZATION is mistitled. At the very least, the volumes produced by Richard Schmalensee and Robert Willig and their cadre of authors are a Two-hand book. Indeed, given the weight of each volume, it would be more appropriate to call the product a Two-arm book. (This is not to be confused with the two-armed bandit of probability theory and consumer search theory, although those aware of the $\$ 157$ price tag might question whether I have too quickly dismissed the latter appellation.)

The substantial product admirably achieves the goal the editors articulate: "Our purpose has been to provide reasonably comprehensive and up-to-date surveys of recent developments and the state of knowledge in the major areas of research in this field as of the latter part of the 1980's, written at a level suitable for use by non-specialist economists and students in advanced graduate courses." The two volumes of the Handbook will indeed "serve as a source, reference, and teaching supplement for industrial organization (or industrial economics)."'1

I am grateful to my colleagues Bruce Ackerman, William Brainard, and Richard Levin for their helpful comments and discussions, and to the discussants Paul MacAvoy and Sam Peltzman for their comments.

1. Both quotations in Schmalensee and Willig (1989, vol. 1, p. xi). 
To be sure, the two volumes are not equally weighty. Volume 1, which is overwhelmingly theoretical, as it contains surveys of the determinants of firm and market organization and the analysis of market behavior, is far larger-in weight and girth - than volume 2, which surveys more applied issues and includes pieces on empirical methods and results, international issues and comparisons, and government intervention in the marketplace. The imbalance between theory and applications is even greater than an eyeing or hefting of the volumes reveals. Although a few of the surveys in volume 1 discuss empirical material, the more applied volume contains a very heavy dose of theory in the contributions of Ronald Braeutigam on "Optimal Policies for Natural Monopolies" and David Baron on "Design of Regulatory Mechanisms and Institutions.',

The predominance of theory in these surveys accurately represents the character of recent research in industrial organization. It lends persuasive support to the perennial plea of editors of journals concentrating in the field for more good applied papers. In their preface, Schmalensee and Willig mention four exciting trends in the field of industrial organization that they believe make preparation and publication of the Handbook particularly timely. One among these is that "new waves of empirical and experimental work in industrial organization are gathering momentum, driven by clarified views of the limitations of the previous focus on cross-sectional interindustry studies, and by the profusion of new hypotheses and possibly testable conclusions produced by the explosion of theoretical work." 2 The relative attention that theory and applications receive in the surveys accurately reflects that while empirical and experimental work may be gaining momentum, they are not yet fully up to the speed of theoretical developments. I shall try, later in this review, to suggest an explanation for this unbalanced growth.

Given the division of labor between Franklin Fisher, in his companion essay in this issue, and me, my remarks here will focus on parts 1, 4, and 5 of the Handbook. These parts survey material on the determinants of firm and market organization, international issues and comparisons, and government intervention in the marketplace. I shall concentrate particularly on the first and the last of these three topics and the connections between them.

2. Schmalensee and Willig (1989, vol. 1, p. xi). 


\section{Content and Style of the Handbook}

The individual chapters are, on the whole, well written. There are, however, many more minor (probably typographical) errors than one would ever want to have remain in such an important compendium. Misspellings, inaccurate cross-references to other chapters, and grammatical slips are numerous. In some cases, as when negations are incorrectly inserted or inadvertently omitted, when (on one occasion) several sentences are omitted, or when important slips in equations occur, the errors significantly impede understanding. One hopes that the upcoming second printing will find them repaired.

The various authors use different approaches to present their material. The variety enhances the readability of the volumes taken as a whole and shows the effectiveness of alternative ways of interpreting the surveyor's task. Some authors provide a systematic exposition of the material, as John Panzar does in "Technological Determinants of Firm and Industry Structure.' This essay is particularly useful in distilling the contributions of the important monograph Contestable Markets and the Theory of Industry Structure, coauthored by Baumol, Panzar, and Willig. Another skillful deployment of this most systematic approach is David Baron's tour de force in expositing the literature on regulatory mechanism design to which he has contributed so much.

Some authors more self-consciously take several steps back from the material they are surveying. This helps them to bring recent work into perspective, to draw together different models, and to shape the central issues currently addressed. It also enables the authors to bring into sharp focus the important questions for future research. Bengt Holmstrom and Jean Tirole very effectively adopt this approach in their fine contribution on the theory of the firm and its contractual basis.

A third type of lens is used by Paul Joskow and Nancy Rose in their essay on the effects of economic regulation. Combining methodological and substantive views of their subject, Joskow and Rose begin with an exposition of alternative frameworks and empirical methodologies for assessing the effects of regulation. They then survey the particular effects of regulation on prices, costs, innovation, product quality, and wealth distribution that researchers have uncovered by using these methodologies.

Finally, in the chapter on the determinants and effects of vertical 
integration, Martin Perry successfully draws together several important strands of literature. He describes and assesses old and new theoretical explanations of why firms at different stages of the production process might integrate their operations. But he also integrates an evaluation of the empirical research that bears on the alternative explanations.

Each chapter is written by a major player in the field, which assures that the reader is getting an expert's eyeview. The various authors also strive to provide a balanced view of the approaches to their subjects. Each writer tries to alert the reader to the problems as well as the contributions of the theory or approach with which he or she is identified. Given the natural enthusiasm of a participant in a research program, however, a somewhat different structure might have been valuable. One or another chapter might have been written by a knowledgeable, but more critical, less sympathetic scholar. Alternatively, and probably even better, each chapter might have been accompanied by a critical comment prepared not necessarily to critique the survey itself but to provide a different evaluative viewpoint on the material covered in the piece. For example, the reader might have come away from the Handbook with a broader perspective if the volumes had contained a critical assessment of the achievements of transaction cost economics by someone who is less of an aficionado than Oliver Williamson, who indeed is its major prophet, and a similar piece on the literature on regulatory mechanism design by someone who is less enmeshed in the subject than David Baron. I choose these examples not because I am unenthusiastic about the work surveyed by Baron and Williamson, respectively, but, on the contrary, because I believe some contributions in these two areas have been transformative.

There are two notable gaps in the parts of the Handbook that I am reviewing. Indeed, the footnotes in the preface suggest that Schmalensee and Willig are as dismayed as this reader that one or another author did not deliver the chapters, which had been planned for inclusion, that would fill these holes.

The first gap is the absence of a systematic treatment of empirical work on the contractual nature of the firm. Such a survey would have naturally complemented the Holmstrom-Tirole survey in the same way as the Noll, Joskow-Rose, and Gruenspecht-Lave chapters on economic regulation and health, safety, and environmental regulation complement the more theoretical contributions of Braeutigam and Baron. There is 
an empirical literature, however slender, on each of the four major theoretical topics considered by Holmstrom and Tirole - the boundaries and character of firms, their capital structures, the role of management (and particularly the separation of ownership and control), and the internal hierarchical organization of the firm. A chapter that told the reader what we know empirically about the various theoretical models that have been proffered on these issues would have been valuable. For example, what effects of separation of ownership and control have been identified? How effective is the market for corporate control, and particularly the instruments of takeover and merger, in generating efficient managerial behavior? What evidence is there that executive compensation schemes provide effective internal discipline mechanisms or even that they succeed in closely linking pay and performance? Do the executive compensation schemes that firms adopt follow the lines that agency theory suggests? With regard to another of the issues that Holmstrom and Tirole treat in their chapter, which of the several arguments about determination of a firm's financing find support in empirical research? Is the debt-equity ratio chosen to provide optimal incentives to management, or is it selected to signal to market participants information that the firm management possesses, or both? How important are the control rights, rather than the residual return stream, that a voting share confers on its owner?

In the course of their discussion of theoretical issues, Holmstrom and Tirole do provide a few brief references to related empirical work. Furthermore, Panzar in his discussion of the econometrics of multiproduct cost functions, Williamson in his review of empirical studies in transaction cost economics, and Perry in his discussion of empirical studies of vertical integration all provide some assessment of what we know empirically about firm formation and organization. But it would have been useful to have these several strands and others - for example, work on labor contracts, capital structures, and executive compensation structures as they reflect the contractual basis of the firm-drawn together. The chapter that Schmalensee and Willig intended to include showing how theoretical and empirical tools from modern financial economics have illuminated issues in industrial organization would have helped here.

The second major omission is the absence of a chapter providing an analysis of antitrust policies and their enforcement. Several chapters 
take up the slack as Perry and Williamson in part 1 and Ordover and Saloner, Varian, and others in part 3 discuss various aspects of antitrust policy. But a more unified treatment of the theory and practice of antitrust law and policy would have been valuable. Such a chapter could have examined the interplay between theory and policy in a number of significant recent developments.

One of these developments is the more sophisticated approach that has been taken to market power, its significance, and its measurement across the spectrum of antitrust law. Another phenomenon of interest is the changing role and content of per se rules against specific practices-price-fixing, for example-and the corresponding expansion in the breadth of application in substance, if not in name, of rule-of-reason analyses. The chapter on antitrust policy could have analyzed the changes in merger law in the last decade and linked them to our new understanding of firm behavior and organization. Two other areas in which recent developments in industrial organization could have been related to antitrust policy are, first, our more sophisticated understanding of vertical restraints and the law's more lenient treatment of them so long as the prices are not involved, and, second, the insights (if any) that work in information economics and strategic behavior provide for the assessment of information exchanges among firms and related facilitating practices. Finally, such a chapter could have taken up issues of antitrust enforcement and, in particular, questions about the role of private litigation, which a number of economists have studied in the last decade or so.

Just as there are gaps in coverage, so there are overlaps as well. But these multiple coverings of the same ground are illuminating, as when Holmstrom and Tirole, Williamson, and Perry all treat the issue of vertical integration-indeed, when they discuss the same work-but from somewhat different points of view. ${ }^{3}$ For Holmstrom and Tirole, it is essential that a theory of the firm be able to explain the occurrence and extent of vertical integration if the theory is to address one of the fundamental issues within its domain, namely, the scale and scope of firms. Williamson treats vertical integration as "the paradigm problem", of transaction cost economics; he believes that an understanding of

3. Grossman and Hart (1986); and Williamson (1971, 1975, 1985). 
vertical integration illuminates much more general issues of complex economic organization.

While Holmstrom and Tirole and Williamson locate their analyses of vertical integration squarely within the incomplete-contracting model, Perry surveys a broader range of explanations of vertical integration, in particular those in which market imperfections are featured. (All three essays briefly mention technological economies that may give rise to vertical integration.) The greater breadth of Perry's treatment is appropriate, of course, because the subject of his chapter is precisely defined as the determinants and effects of vertical integration.

Similarly, Noll, Joskow and Rose, and Gruenspecht and Lave all discuss aspects of the interplay between politics and economics in regulatory settings. For Noll, that interplay is the focal point of his interpretative survey on the politics of regulation. The other two chapters treat political economy issues within the context of the particular type of regulation they are examining. Joskow and Rose view the political economy approach to regulation, with its emphasis on the interaction among interest groups for whom particular regulatory measures carry different costs and benefits, as a framework within which to assess the effects of economic regulation. They pay particular attention to what research on the political economy of regulation has revealed about the distributional effects of regulation and deregulation. Gruenspecht and Lave attend to the political origins of health, safety, and environmental regulation. They also describe how the political economy approach illuminates the formulation of goals for agencies and the rents that such social regulation generates.

The various overlaps in coverage are useful because they provide different perspectives on the same phenomenon or at least demonstrate different contexts in which it is relevant. But the overlaps are also interesting because they identify several Schelling points, as it were, of work on the theory of the firm and government regulation of the marketplace.

\section{Trends that Motivated the Editors}

One does not know, of course, whether the several trends that Schmalensee and Willig identify as coming together to make the Handbook's 
appearance so timely were ones they sighted before or after they saw the papers. But all of these trends are salient in the three parts of the Handbook I am reviewing here.

I have already mentioned the gathering momentum of empirical and experimental research to which the editors refer. A second principal development they cite is the "recent and ongoing revolution that is reexamining all microeconomic phenomena as strategic interactions with explicitly-specified (and often asymmetric) information structures,' which they observe is particularly focused on industrial organization. ${ }^{4}$ The surveys of the determinants of firm and market structure and government intervention in the marketplace make abundantly clear the large formative role the information economics revolution, and especially analysis of the effects of asymmetric information, has played in deepening our understanding of the economics of the firm and the economics of regulatory interactions. As Holmstrom and Tirole emphasize, for example, it was the development of information economics in the 1970s that provided the basis for the recent analysis of the organizational structure of firms, which "has centered on an improved understanding of how one goes about contracting when people know different pieces of information of relevance for the organization as a whole.",5

Similarly, the centrality of information economics and strategic analysis to the literature on the design of mechanisms to govern firm-regulator interactions is announced by Baron at the outset of his contribution: "The focus of this chapter is the design of regulatory policies that take into account the opportunities for strategic behavior provided by incomplete and limited observability on the part of the regulator." 6 Whether or not adoption of the information-economics perspective constitutes the replacement of one Kuhnian paradigm by another, because of developments in information economics we now view both firm organization and regulatory interactions very differently than we did twenty years ago, and there is no turning back.

The third trend to which the editors allude is the blurring of the traditional boundaries between historically different fields of economics. They observe that the perfectly competitive model, which had been central

4. Schmalensee and Willig (1989, vol. 1, p. xi).

5. Schmalensee and Willig (1989, vol. 1, p. 64).

6. Schmalensee and Willig (1989, vol. 2, p. 1349). 
to fields such as international trade and macroeconomics, is being replaced by imperfect-competition models drawn from industrial organization. This development is certainly apparent in the literature Paul Krugman surveys under the heading of "Industrial Organization and International Trade." Models of Chamberlinian monopolistic competition as well as models of duopoly in which firms deploy various tools of strategic behavior are prominently featured in this literature and in Krugman's review.

Finally, Schmalensee and Willig observe that developments in the policy arena have contributed to the excitement of industrial organization. "[A] bevy of significant policy issues squarely in the domain of industrial organization has been at the forefront of public and political attention in recent years," they write. ${ }^{7}$ Among the issues the editors mention are takeover and merger activity, the movement toward deregulation, and the increasing globalization of competition. Not only do these issues draw researchers directly into the policy arena, but they also provide an important impetus to theoretical and empirical research.

The links between policy issues and research developments, both theoretical and empirical, are apparent not only in the chapters directly focused on the politics and economics of regulation but also in the more theoretical contributions. For example, much of the work that Panzar surveys on technological determinants of firm and market structure was stimulated by antitrust and regulatory cases in the 1970s that involved large multiproduct firms. A good bit of the literature on the design of regulatory policies and mechanisms, which is reviewed in the Baron and Braeutigam chapters, had its origins in some of those same cases and, with respect to material Baron covers, in concerns about controlling pollution by firms that have different production technologies and more information about those technologies than the regulators possess. Many theoretical inquiries that introduced imperfect-competition models in international trade, of the type reviewed by Krugman, were stimulated by the increasing globalization of competition, accompanying concerns about the competitiveness of U.S. industry, and complaints about the restrictive trade practices of various countries. The conceptual developments in the theory of the firm, and transaction cost economics in particular, were related to policy concerns about mergers, takeovers, and other corporate restructurings. The policy-research agenda nexus would have been even

7. Schmalensee and Willig (1989, vol. 1, p. xii). 
more clearly illuminated had the Handbook contained the missing chapters on antitrust policy (for example, vis-à-vis mergers, facilitating practices, and predation) and financial economics contributions (with regard to issues such as mergers and takeovers and the market for managers).

\section{Inward to the New Frontier}

Three other tendencies seem to me to mark recent developments in the literature surveyed in the substantive bookends, parts 1 and 5, of the two volumes of the Handbook. First, much recent research on the theory of firm and market organization and on government intervention in the marketplace has systematically unpacked the concepts we had, for the most part, previously taken as primitive to our analysis. Another way to describe this development is to say that recent literature in industrial organization has taken as a major concern the treatment of microeconomic structures and relations as endogenous or at least as more endogenous than they were treated before.

"'The firm' in today's industrial organization discourse is a much richer concept than it was twenty-five years ago. And this is so even though leading contributors to the literature, such as Holmstrom and Tirole, characterize this field of inquiry as still "young and immature." 8 The firm is no longer a lifeless production or cost function with a manager facing spot prices and mechanically selecting the profitmaximizing input-output combination from the technologically feasible set. The relations among the firm's owner(s), its manager(s), its workers, and its capital and materials suppliers are now to be understood as the result of optimization decisions by agents making choices within the technological and transactional environments (including information structure and human characteristics, like bounded rationality and opportunism) they face.

Similarly, our understanding of "regulatory constraint" is much deeper than it was. This greater depth is an awareness not just of the unintended (as well as intended) effects that imposing regulation can have but of the complexity of what it means to impose a regulatory constraint on a firm. Regulatory policies are modeled not as simple

8. Schmalensee and Willig (1989, vol. 1, p. 64). 
constraints imposed on a mechanically responsive firm but as endogenous outcomes of the interactions among political constituencies, legislators, regulators, and the regulated entities. Again each player is viewed as making its decision within a well-specified technological and strategic (particularly, information) environment.

To be sure, these more profound understandings of basic concepts in industrial organization and regulation did not spring full-blown in the last period of time. Each set of developments had its precursors. For example, Oliver Williamson's chapter on "Transaction Cost Economics" traces the origins of that literature's contribution to our understanding of firm formation to the work of Coase, Commons, Barnard, and Llewellyn in the 1930s. Roger Noll, in his chapter on "Economic Perspectives on the Politics of Regulation," also cites, though briefly, the precursors of George Stigler's seminal 1971 article, "'The Theory of Economic Regulation.'” Arguably, however, it was Stigler's contribution that started the surge in literature on the political economy of regulatory policy. ${ }^{9}$

Overall, this emphasis on examining and understanding entities and relations that we had taken as given-the firm, the regulatory constraintpervades the recent literature on which the Handbook contributors focus. The mission of the industrial organization literature remains to understand the behavior of a particular set of economic agents and the implications that behavior has for market structures and processes, economic performance, and public policies toward the marketplace. But we now develop explanations and predictions of those agents' behavior starting from a more microanalytic level than we had before.

\section{The Interdisciplinary Reach of Recent Research}

A second characteristic of recent research on the theory of the firm and government intervention in the marketplace is its interdisciplinary character. The work of Williamson and others on transaction cost economics explicitly combines the insights of legal scholarship and organization theory with those of economics to explain the origins and functioning of firms and other economic institutions. Strong links between economics and accounting have also been forged as theories of 
firm structure and hierarchies have focused on incentive mechanisms and monitoring in principal-agent relations. The confluence of the concerns of designers of modern accounting systems and those who seek to explain incentive structures in firms is apparent in the Holmstrom and Tirole chapter on the theory of the firm.

Despite the importance of concepts such as bounded rationality and opportunism in these modern theories of the firm, the Handbook chapters on this subject contain virtually no citations to the recent literature on individual psychology. Several pieces do cite Herbert A. Simon's seminal work Models of Man, published in 1957, for its discussion of bounded rationality and its implications. Insofar as the theories of the firm aim to explain the structure and governance rules of organizations when individual agents are less than the omniscient, fully rational characters of more traditional models, it would seem that the insights psychologists have to offer into human behavior, particularly with regard to gathering and processing information and acting upon that database, would be pertinent. ${ }^{10}$

Some research of cognitive psychologists is noted by Gruenspecht and Lave in their discussions of risk assessment and the setting of riskreduction goals. Furthermore, in recent work, Roger Noll and James Krier have brought some of the learning of cognitive psychologists to bear on the demand for and supply of regulation of risk. ${ }^{11}$ But there seems to be much more scope for infusion of ideas from these psychologists in industrial organization and especially in new theories of the firm. For example, conventional expected-utility maximizers remain the central actors in many formal models in the modern contractual theory of the firm. Some cognitive psychologists have found, however, that people systematically depart from the conventional mode of decision analysis when they make choices under risk and that some common kinds of mistakes occur in the assessment of the relevant probabilities. What are the implications of these findings for the formal contractual models and the theories that build upon them? Can the observed departures from conventional analysis be incorporated to yield new predictions about firm structure?

As the Noll, Joskow-Rose, and Gruenspecht-Lave chapters all make

10. See, for example Kahneman, Slovic, and Tversky (1982).

11. Noll and Krier (1990). 
clear, work on economic regulation has increasingly joined with work in political science and law in trying to understand better the origins as well as the effects of regulatory policy. The effort has been aimed at developing a sound, microeconomically based theory of the political behavior that leads to the creation and direction of regulatory institutions. This is neither an intellectually imperialistic attempt to take over the political scientists' and legal scholars' understanding of regulation and its origins nor a desertion of the field of concerns with the economic effects of regulation.

The intensified interaction with political science and law is, instead, a natural consequence of the broadening, in the last twenty-five years or so, of the issues that are understood to lie within the domain of the economics of regulation. As more effort has been devoted to asking why a particular set of regulations has been put in place and those regulations are administered the way they are, the desirability of drawing upon political scientists' theories of interest-group politics and legal scholars' understanding of the administrative process is apparent. "The details of political and economic institutions and how they affect both distributional and efficiency consequences of policies' ' have become a central issue in modern theories of regulation. ${ }^{12}$

As the evaluative reviews by Noll and by Joskow and Rose make clear, these inquiries into the political economy of regulation are still at an early stage, and the theory in this area leads by a considerable margin our accumulated quantitative results. Furthermore, as Joskow and Rose emphasize at the end of their chapter, "The work on the political economy of regulation must inevitably be carefully related to the effects of economic regulation and the way economic regulation is accomplished. The politics and economic consequences of regulation are intertwined in complex ways.', 13

\section{The Role of Law in Theories of the Firm and Regulation}

Reading parts 1 and 5 of the Handbook together suggests a third additional theme, albeit one less explicit than any of the others I have

12. Schmalensee and Willig (1989, vol. 2, p. 1262).

13. Schmalensee and Willig (1989, vol. 2, p. 1498). 
discussed. It is the convergence of the literatures of the theory of the firm and government intervention in the marketplace.

One might begin by noting the commonality of the references in part 1 's chapters on the theory of the firm and the works cited in the more theoretical chapters on regulatory institutions. In part that commonality reflects the fact that both topics fall within the field of microeconomics. Hence, both have been dramatically affected by the recent informationeconomics and strategic-interaction revolution that is still going on in the study of microeconomic phenomena. But the set of specific references that the recent literature on the theory of the firm shares with the work on government intervention is broader. For example, the same multiproduct cost function concepts that John Panzar presents and then applies to the determination of firm and industry structure are central to Ronald Braeutigam's presentation of the analysis of "Optimal Policies for Natural Monopolies.',

\section{The Theory of the.Firm and the Legal Structure}

More fundamentally, however, the two literatures are converging because the ideas that have become central to the literature on the theory of the firm implicate a legal and regulatory framework. A defining characteristic of the recent research on why firms exist and how they are structured is its emphasis on incomplete contracts and, in one approach, property rights. The concept of what is contractible is central to recent analyses of the choice between relying on arrangements within a firm versus depending upon market transactions. An attractive feature of Martin Perry's chapter on the determinants and effects of vertical integration is his effort to relate the concept of incomplete contracts invoked in the literature on the theory of the firm to features of contract law, to wit, treatment by the Uniform Commercial Code and the courts of conditions precedent and indefinite contracts. A paper by Alan Schwartz, "Legal Contract Theories and Incomplete Contracts,", explores in greater depth the connections between the incomplete contracts of theorists' models and the doctrines of contract law as the courts apply them. ${ }^{14}$

Furthermore, discussions of hierarchical relations within firms nec-

14. Schwartz (1990). 
essarily draw upon ideas about authority and rely on assumptions about which actions by occupants of different levels of the hierarchy will and will not be enforced. Holmstrom and Tirole include in their survey a brief discussion of the role of authority, particularly its delegation, in the internal hierarchy of the firm. Previewing the subsection, they caution the reader, though, that their discussion makes "little reference to models for the simple reason that there is almost no formal work" on the topic and that their remarks on it are "intended to bring attention to a big gap in formal theorizing about the firm." In the discussion itself Holmstrom and Tirole remark that "authority-its scope and entitlements - is a rather elusive concept.", 15

Incomplete contracts, authority relations, and related concepts, and the approaches that build upon them, presuppose a legal structure or a set of social norms that establishes what rights individuals (and groups) have and how those rights will be enforced. Although recognition of legal constraints has always been an essential part of the economics of regulation, the central role of legal rules in the theory of the firm is new-a far cry from the features on which the standard (textbook) neoclassical theory of the firm focused.

To see how important a legal structure is to the new economic theory of the firm, consider the two major necessary conditions for contractibility of a transaction: observability and verifiability. Each of these requirements entails the physical capacity to undertake a particular act. As to observability, a party must be able to determine, by some sensory mode, whether a particular event has occurred; with regard to verifiability, one or another party must be able to display to a third party what has transpired and that outsider to the transaction must be able to discern that reality. There are not only physical requirements for each of these preconditions to contractibility, but resource requirements as well. It takes resources, at least some time and effort, to observe an action, and it surely requires resources for parties to a transaction to provide the necessary data to a third party and for that third party to reach a judgment about what has, in fact, occurred.

Observability and verifiability also take as given certain features of a legal system. That is transparent in the case of verifiability. A third party (whether a court or another dispute-resolving institution) must be

15. Schmalensee and Willig (1989, vol. 1, pp. 107, 123). 
provided, rules must be set for how the third party will go about verifying what occurred, and all parties must share an understanding of what force the third party's verification will have. But the role of the law is as important with regard to the essential element of observability because the set of legal rules or social norms will determine what can and cannot be observed, what information economic agents need to record and to make available, and what entitlements to nondisclosure one or another party possesses.

Indeed, the asymmetry of information that gives rise to the problem of observability is itself a function of the legal system or set of social norms governing the society. The significance of the informational asymmetry, and particularly whether it gives rise to what Williamson calls information impactedness, depends, as he has stressed, on the costs of achieving informational parity. But those resource costs depend on the assignment of rights to information that the legal system makes and the mode of protection it provides. The cost of achieving symmetry in the information available to the parties depends on what the law stipulates about the conditions under which and the terms upon which one party will be able to secure information from another. The information base itself may well depend on the kinds of data the law requires a party to obtain and to retain about itself.

\section{Regulation and the Legal Structure}

As recent work in industrial organization has unpacked central concepts in microeconomics - in particular, the firm-some of the more primitive concepts have thus turned out to be laden with legal content. Central features of our modern understandings and theories of the firmcontractibility, commitment, authority - are rooted in the legal structure. As I shall illustrate by focusing on parts of David Baron's chapter, this is even increasingly the case in regulatory economics, which has always had to be attentive to the character of the public regulatory intervention.

Since regulatory interactions are now more explicitly analyzed as equilibria of well-specified games, as noted in the literature Baron surveys, it becomes even more important to specify with great care " the authority granted to the regulator," for it is this authority and the 
limits on it that dictate important parts of the game's structure. ${ }^{16}$ Furthermore, as the regulator's incomplete information about the firms it regulates and the regulator's limited ability to observe those firms' actions take a central place in the theory of designing regulatory institutions, the legal structure is once again implicated, just as it is in the new theory of the firm. This involvement is most apparent when the regulator has the authority to command certain information from the firm and to monitor the firm's performance, a realistic situation depicted in a set of models that Baron reviews. But consider, more generally, regulatory schemes that are intended to provide the subject firms with a fair return or adequate profits. As Baron writes, "In regulatory contexts with informational asymmetries, the adequacy of the profit of a firm must be relative to information that both is observable by all parties and is verifiable by a third party with enforcement powers. " 17 In short, a regulatory scheme that guarantees the firm a fair return must be contractible, and hence such an arrangement presupposes a legal structure the same way a privately contractible transaction does.

Baron also stresses the difficulty of designing regulatory mechanisms and institutions in a multiperiod setting, which is the situation most actual regulators face. The problem is how to avoid, or at least to limit, opportunistic behavior on the part of the regulator and the firm and the inefficiencies that attend such behavior. Opportunism will arise on the regulator's part because the regulator "wish[es] to design the mechanism to be responsive to the evolution of information and performance", as uncertainty is resolved and demand and technology conditions change. "This requires some means of committing not to act opportunistically when doing so would result in ex ante inefficiency,"' Baron writes. ${ }^{18}$

Baron believes that attaining commitment is particularly difficult when governments or public agencies are players. He is dubious that the regulator has means of endogenously generating commitment that are comparable to those the parties have in private contracting. Baron goes on to explore the possibility that the regulator and the firm might be motivated "to reach a voluntary arrangement in which the firm is

16. Schmalensee and Willig (1989, vol. 2, pp. 1349, 1351).

17. Schmalensee and Willig (1989, vol. 2, p. 1411).

18. Schmalensee and Willig (1989, vol. 2, pp. 1391, 1392). 
offered some protection from the actions of the regulator and, in exchange, limits its ability to withdraw from the arrangement.' He uses the term "fair" to characterize a regulatory relationship in which the firm forgoes its right to withdraw from the relation and the regulator is required "to choose policies that are compensatory given the information revealed by the firm in earlier periods." 19 Apart from that restriction, the regulator is unconstrained; each period the regulator can choose a policy that is optimal given the information it has.

In an example Baron presents, which he and Besanko devised, the regulator and the firm both prefer the fairness arrangement to what they can attain with no commitment. The result, however, is not a general one, as Baron notes. He also observes that despite the difficulties agencies and governments have in making commitments, legal structures and institutions-common law precedents, statutes setting out both substantive and procedural requirements, legislatures, and courts-provide another way to create fair regulatory relations. By providing a framework that raises each party's level of commitment-the regulator's to provide an adequate return, the firm's to remain in the marketthe legal structure reduces the parties' need for inefficient sinking of resources to demonstrate their commitment. Note, furthermore, that even if the fair regulatory arrangement were arrived at voluntarily, as in the Baron and Besanko example, a need would still exist for a background set of legal institutions to enforce the agreement over time.

Another potential convergence of some work on the theory of the firm and the literature on regulation is suggested by Baron's use of the word fair to describe a regulatory relation with particular characteristics. Although the characteristics he ultimately associates with the termadequate profit for the firm and no exit by the firm-more plausibly describe outcomes than processes, Baron's motivation is to constrain the opportunism each party can exercise. In that sense, he is concerned with aspects of the process itself, not just with the outcomes it generates.

The more empirical surveys of regulation also reflect the concern of this branch of industrial organization with issues of process in specifying regulatory goals, enacting regulatory statutes, and administering regulatory rules. For example, Gruenspecht and Lave observe that in the area of federal health, safety, and environmental regulation, Congress

19. Schmalensee and Willig (1989, vol. 2, pp. 1405-6, 1410, 1411). 
has not legislated clearly stated goals but has, at least implicitly, relied on administrative procedures and decision frameworks, which it has delineated, to generate the goals. Congress has engaged, as Gruenspecht and Lave characterize it, in "defining social goals through process." 20 When taken together, requirements that agencies give notice of consideration of particular regulations, receive the views of the public, and explain their decisions specify a process from which emerge not only particular rules but also the goals of regulation in the area.

In his chapter on the politics of regulation, Noll reminds us, however, that legislators may not always have high-minded motives for leaving goal articulation to the interstices of regulatory agency decisions. He refers to Morris Fiorina's point that the elaborate fact-finding procedures in regulatory statutes may be a device for lifting the responsibility for difficult, conflict-laden decisions from the legislators' shoulders and placing it on those of the bureaucrats. The only definite policy preference expressed by the coalition responsible for the statute may be "that the issue be resolved in an adversarial, evidentiary process that is constructed to reach some sort of compromise." 21 The legislators can, and do, specify procedural details to control the policy outcome by determining, for example, who will be represented in the decision process. Noll's discussion of the effects of the procedural requirements of the National Environmental Protection Act of 1970 convincingly illustrates the use of procedural details to shape policy outcomes. Viewed, complementarily, from the perspective of an agency administering a statute, changes in the stringency of regulation can be effected by subtle changes in process and need not await the passage of dramatic legislation.

Characteristics of process - for example, openness, fairness-are valued for themselves as well as for their role in specifying goals and producing programs. It is noteworthy, therefore, that one of the developments Oliver Williamson sees in prospect in transaction cost economics is that "transaction cost arguments will be qualified to make allowance for process values such as fairness that now appear in a rather ad hoc way.',22

20. Schmalensee and Willig (1989, vol. 2, p. 1532).

21. Schmalensee and Willig (1989, vol. 2, p. 1279).

22. Schmalensee and Willig (1989, vol. 1, p. 178). 


\section{The Imbalance between Theoretical and Empirical Work}

The convergence between the analysis of the firm and its organization and the analysis of regulation suggests one possible explanation for the imbalance between theoretical and empirical research in industrial organization in recent years. Observe that most of the empirical work reviewed in the Handbook is a set of studies of firms interacting in markets. Although a large number of the studies surveyed proceed within the conventional structure-conduct-performance paradigm, a substantial segment of the work-in particular, that which Bresnahan labels the "new empirical industrial organization" - draws on the recent outburst of theoretical analysis of market behavior. There is much less empirical work that capitalizes on new developments in the theory of the firm.

One of the major lessons of research on economic regulation, especially as reviewed by Noll, Joskow and Rose, and Gruenspecht and Lave, is that in analyzing the effect of regulation, the researcher must be exceptionally attentive to institutional detail. It does not suffice simply to represent the firm subject to regulation as the paradigmatic neoclassical firm subject to an additional constraint. Furthermore, when the effects of regulation are explored by empirical comparisons with unregulated firms or unregulated periods, it is imperative, as Joskow and Rose stress, to be precise in defining " what legal institutions (common law, franchising, etc.) actually exist in the 'unregulated' regime. 'Unregulated' markets may in practice be markets subject to a different form of regulatory restrictions (e.g. municipal franchise regulation rather than state commission regulation), not markets subject to no regulation at all., 23

To the extent that legal institutions and regulatory frameworks serve as foundations for our models of firms and our understandings of how they are formed and organized, the lesson of research on regulation applies with force and makes high-quality empirical research more difficult than ever. To be sure, some high-quality work is going forward. As one example, Paul Joskow's several studies of contracts in energyrelated industries stand out, I believe, for the attention he pays to institutional detail.

23. Schmalensee and Willig (1989, vol. 2, p. 1453). 
In several related papers, Joskow carefully-indeed, microscopically-studies the structure of transactions between electric utilities and coal suppliers. ${ }^{24}$ The analysis requires that attention be paid to the specific terms in contracts, the character of investments in different assets, and the details of internal firm structure as well as to more customary firm- and market-level measures. The payoff to this transaction-level examination is an understanding of the very important role that relation-specific investments play in determining the vertical structure of this industry. We learn how such investments affect the choice between market contracting and vertical integration and how, when the former mode is selected, those investments influence the selection of terms in the contract between a utility and the firm supplying it with coal. Joskow's work also shows how contracts in the industry can be and are written to protect idiosyncratic investments of both buyers and sellers. The protection is incomplete, however, and carries with it the potential costs of impeding efficient adaptation to changes in market conditions.

The challenge is not simply to understand the important features of legal and economic institutions but to distill that knowledge into observations about variables that can be used for empirical testing. Moving from the theoretical formulation to empirical investigation, the researcher has to develop operational measures of concepts that are central to the new theories of the firm-for example, the concept of asset specificity in transaction cost economics. The difficult conceptualization involved in performing these tasks, not to mention the hard work of basic data collection itself, was bound to slow the pace of empirical work in industrial organization as these new theories appeared.

The information-economics revolution has generated yet another set of problems for those who would put modern theories of industrial organization-particularly work on the theory of the firm and government regulation-to the test. The explicit specification of information structures and sequencing of agents' moves has become an essential element of microeconomic modeling. Hence, empirical researchers who would test such theories must be equally explicit about information sets and strategies in their empirical models and data. The econometrician must carefully distinguish between the information that was available 
to the parties when they acted and the data he or she observes and uses in the empirical analysis. Just ascertaining what information economic agents had at some time in the past is no simple task; indeed, in some circumstances it may be impossible. In modeling dynamic interactions, the econometrician must also be explicit about how information unfolds over time.

Not only are the formulation of the empirical model and the collection of data more difficult when the information structure is critical, but the interpretation of results and the drawing of inferences are more complicated. The appropriate conclusion may well depend on what the parties knew at the time they acted. Baron provides a cogent example:

Suppose that, after the fact, the econometrician had data on actual costs and the price that had been set in a period. If the price were equal to the actual marginal cost yet information had been incomplete at the time the price had been set, the conclusion that should be drawn is that regulation was inefficient, since price should have been above marginal cost (except in the case of the lowest conceivable cost). Similarly, if the price had been above actual marginal cost, the econometrician could not conclude that regulation had been inefficient. ${ }^{25}$

Hence, the conclusions drawn from the comparison of price and actual marginal cost that would be appropriate if information had been symmetric could be quite misleading if, in fact, the regulator and the firm did not have a common information set. Of course, as Baron goes on to observe, the econometrician may be able to use other data to assess the efficiency of regulation. In static situations, data on rents earned by the firm could be used, and in dynamic settings the time paths of prices and costs could help.

Hence, econometric modeling and estimation of models with complicated, evolving information structures is more demanding than the kind of empirical work that was required to test earlier theories of firm, market, and regulatory behavior. Because of the multiplicity of difficulties-including reducing theoretical concepts to operational terms, ascertaining the relevant information sets of different agents at various points in time, and interpreting the results-there are serious questions about the feasibility of the enterprise. Moreover, while it is unclear

25. Schmalensee and Willig (1989, vol. 2, p. 1439). 
how much any one such study will illuminate, it is even less certain how far we will be able to go beyond specific case studies. The scope for generalization seems severely limited when the empirical model must be so finely tuned to the specific information and strategic structure.

\section{Some Implications for Policy}

The recent directions in industrial organization research have implications for policy analysis and for microeconomic policy itself. I suggest just two here.

First, our deeper understanding of the nature of the firm implies the need for greater attention to the complexity of firms when designing policy. We have long known that when the imposition of regulatory controls is contemplated, the policy analyst must take account of the ways in which the firm will respond. The recent literature suggests the importance of recognizing the legal structure that provides the background against which those adjustments will take place. For example, in assessing the effects of switching to or from an automatic adjustment mechanism for one or another type of cost in utility rate-setting, it is important to take account of contract law provisions that circumscribe the way the firm can respond. Similarly, the ways in which utility commissions decide allowable costs of suppliers will affect firms' choices about vertical integration and the kinds of contracts that regulated firms will enter with suppliers. But those contracts and integration decisions will also be affected by the background rules of contract law. Furthermore, as relevant background legal rules evolve over time-for example, product liability law, environmental law, contract law-these developments will affect regulated firms just as they do other enterprises, and these effects may reverberate on the firms' responses to regulation.

Second, the contemporary view of the firm as a mode of organization that is endogenously chosen raises interesting questions about the firm's role as the central unit of antitrust analysis. The Supreme Court most recently faced this issue in Copperweld Corporation v. Independence Tube Corporation, a 1984 case in which the Court held that a parent corporation could not conspire with its wholly owned subsidiary in the 
legal sense contemplated by Section 1 of the Sherman Act. Lower courts have since considered, and divided on, the issue of whether such conspiracy could occur between a parent corporation and another corporation that it partially owned.

Given that we now better understand the firm as a single endogenously chosen point on a continuum of relations among economic agents, why should that type of organization be the starting point for analysis of antitrust issues? And if the answer, as in Copperweld, is that sometimes the corporate veil should be pierced in antitrust law, what implications does that have for the relation between antitrust and other areas of law-for example, tort-where the apparent separateness of corporate entities (and the limitation on liability it implies) is generally respected? 


\section{Comments and Discussion}

Comment by Paul MacAvoy: Alvin Klevorick's appraisal is methodologically definitive as well as impressively comprehensive. I am left only with issues of content. Specifically, Klevorick strongly approves the linkage from policy to new theory. My disapproval results from my being unable to find linkage in the opposite direction.

Having been occupied as a business school dean in the 1980s, I came to the Klevorick paper, and ultimately to the Handbook of Industrial Organization, without having read the recent research literature on industrial organization. ${ }^{26} \mathrm{My}$ perspective is that of someone seeking to determine from these sources the causes and effects of regulatory "reform." Beyond that I am looking for more efficient management practices of regulators to be found in the new theory.

In the 1970s, regulation had new, significant impacts on important sectors of the economy. The process of controlling tariffs in the energy, transportation, and communications industries became increasingly destructive as the regulatory agencies severely constrained price increases during periods of high inflation. ${ }^{27}$ At the same time, equipment stan-

26. If any professor believes that functioning as dean is compatible with keeping up with the journal literature, then I invite him or her to apply - there are fine deanships open in the top thirty business schools each year.

27. Joskow and Rose in their essay on empirical findings do not focus these findings on the relationship of regulation to general economic conditions. Instead they describe various analyses of the effects of regulation by industry. But on p. 1467 they conclude that regulation both increases and decreases prices, depending on the context; referring to the business cycles of the 1970 s, they find that "regulation seems to bind most when nominal prices are rising quickly." In the conclusion of their article they note that "macroeconomic disturbances of the 1970's . . . have been characterized as the most severe disruptions since the 1930's . . . [and these gave rise to] the recent wave of Federal regulatory reforms." Their supporting evidence for this last, and most important, conclusion is scant. See Schmalensee and Willig (1989, vol.2 pp. 1467, 1497). 
dards to meet health, safety, and environmental requirements reduced GNP growth rates by one-half to 1 percentage point a year in the 1970 s in the eight most regulated manufacturing industries. ${ }^{28}$ There were no commensurate economywide benefits from either holding down prices in the utility industries or adding to costs and price increases in the newly regulated health, safety, and environmental (HSE) industries. ${ }^{29}$

To construct theory that explains this pattern requires determining whether it was caused by either the method or the purpose of regulating. All the agencies limited company or average industry revenues to the level of book costs plus a return on investment set by discounted cashflow estimates of earnings in other industries. The lag of book costs and comparable industry earnings rates behind current long-term marginal costs during periods of rapid inflation caused consistent application of this system to result in regulated prices set too low. Even so, this method conceivably was second-best in the absence of full information with large case-by-case transactions costs. But in this period the agencies were also pressured by new special interest groups whose measure of success was a constant nominal price level. The public interest theory provides the first description, but the interest group theory establishes the second description. The five essays related to public regulation do not select and order the available evidence to allow the reader to confirm one or the other.

Similar problems arise in developing theory to describe HSE regulation in the 1970s. The adoption of design or equipment standards for compliance with health standards could be excused as a second-best adjustment to a significant lack of information about relationships between health conditions and individual company production, stack emissions, and so on. But interest groups directly benefited from cost

28. The magnitudes of GNP growth effects from regulation are not assessed for economic regulation in Joskow and Rose, although they are cited for health, safety, and environmental (HSE) regulation in Gruenspecht and Lave. There are numerous congressional staff reports, studies done for testimony in hearings, and submissions before the regulatory commissions that assess GNP effects sufficiently to allow the analyst to determine these effects, however. One has to look elsewhere than in the Handbook.

29. Gruenspecht and Lave state that results to date indicate that "the predominant benefits of HSE regulation come from mitigating human health problems." They go on only to discuss the methodological problems of measuring such benefits. They do not review prominent estimates in other important sources. See Schmalensee and Willig (1989, vol. 2, p. 1534). 
advantages imposed by equipment requirements or by avoiding what otherwise would have been the direct costs of performance standards. It was not by chance that the air pollution control process set stringent or militant goals at the federal level, while implementation occurred at the local level where the state regulator had encountered the negative feedback in employment reductions and therefore had to moderate enforcement. Perhaps Gruenspecht and Lave did not have sufficient evidence to establish whether the high-cost, low-benefit results from HSE regulation in the 1970 s were a mistake because of a poorly functioning regulatory system operating in the pubic interest or were results that could be expected when specific interests of members of Congress are served.

During the 1980 s these regulatory effects practically ceased. Prices for utility and common carrier transportation services increased at rates implying cash-flow parity with other industries, and price increases in the most regulated HSE industries moderated commensurate with greatly reduced annual cost increments from regulation in tiose parts of the economy. (To be sure, prices in the automobile and construction industries still were sharply affected by cost increases related to regulation.)

The explanation could be that substantial reductions took place in the scope of regulatory activities. There was a virtual disappearance of regulation of interstate transport, energy production and distribution, and telecommunications. ${ }^{30}$ Federal HSE regulatory enforcement was reduced to nonexistence during the Reagan administration. But regulation within the states was not cut back-there was no deregulation or suspension of commission operations in the state governments.

If one searches the Handbook for explanations about less federal but more state regulatory activity, one can find some clues. Noll's development of the public interest theory implies that deregulation should be observed when the costs of regulation exceed those of decontrol. Certainly the regulation-induced shortage of natural gas and deteriorating rail service imposed costs that qualified these industries to be first in line for deregulation. But the pathbreaking deregulatory actions

30. A Federal Communications Commission regulation of interstate long-distance telephone services will probably not be eliminated until "price caps" on AT\&T rates exceed prices set by companies. 
were in airline passenger service and stockbrokerage, where the results from controls were much less costly (and the transactions costs of decontrol were not dissimilar). Further, the most costly and least beneficial regulatory process has been in emission controls on industrial and electricity production. That process was recently made worse by the Clean Air Act of 1990, an act which is perhaps the most comprehensive law yet passed based on production limits that impose new, very large costs without reference to benefits. Without reviewing all the cases, the theoretical deregulatory priority ordering by "net regulatory costs" seems to have been reversed in practice.

But there is another theory. Noll states that "as regulation becomes more complex with more groups receiving favors the opportunity arises [for the destruction of the process] at the higher level of overall policy.",31 He suggests that new technology causes this increased complexity and reduces the cost of deregulatory transactions. But his interesting essay provides no linkage of technological change to airline, railroad, brokerage, or trucking deregulation (and telephone deregulation, which can be linked to new technology, is the least complete at both federal and state levels). Joskow and Rose review the studies of price changes after decontrol that indicate gains by some and losses by other groups, but they do not bring together these findings to support an interest group theory of regulatory reform.

Much the same pattern of adverse effects in the 1970s, followed by decontrol in the 1980s, took place in the antitrust courts in this country. Given the federal cases brought against AT\&T, IBM, and Eastman Kodak in the 1970s, it appeared as if growth of dominant firms by use of new technology or from marketing advantages would be foreclosed. But these cases collectively failed to penalize the dominant firm, and lower court decisions since then have essentially closed out such proceedings. Since antitrust is the most comprehensive regulatory system in this country, one might ask why this reversal took place in the last decade. Indeed, it is difficult even to determine what institution gets credit for changing policy. The Antitrust Division set other terms for terminating the trials in the AT\&T and IBM cases, and Judge Kaufman on appeal reversed that part of the decision against Eastman Kodak on

31. Schmalensee and Willig (1989, vol. 2, p. 1268). 
the conduct of the dominant firm. There is no foundation in the Handbook for developing an explanation for current relaxation of antitrust.

Of course, it may be premature to ask the Handbook to provide economic insights into the causes for changes in public policy. But the new theory of the firm should help one anticipate the development of markets (isn't that what the theory is about?). Spot field markets for natural gas and futures markets for baseload electricity have developed from nonexistence to the multibillion-dollar level each year in the past three or four years. Markets for display rights in airline passenger reservation systems and for transportation of electric power or natural gas have produced types of contracts never before seen in these now partially regulated industries. Some of the new contracts have been more than imperfect, with high transactions costs relative to sales prices and terms determined by suppliers with market power. Did these innovative institutions become a cause for deregulation, or were they a consequence? Baron's essay provides some new clues to an answer, with respect to the new spot and futures energy markets. Both replace regulatory agreements in which the regulators had developed patterns of highly opportunistic pricing behavior, and both operate as much as possible outside of regulation.

The answer may help us understand why markets for pollution reduction credits have not developed, even though they were proposed by economists to reduce regulatory costs fifteen years ago. ${ }^{32}$ The Clean Air Act of 1990, while requiring costly reductions in emissions from eastern power plants, supposedly reduces costs partly by allowing trading in emission rights among these sources (so that those with advanced stack cleaning technology can reduce their pollutant emissions cheaply by more than what is required, so as to sell off the excess reductions to others). But what if such markets do not develop because of "too high" transactions costs owing to regulatory requirements for trading or because of the market power of a few large electric power producers? What imperfections does it take to prevent a new market from emerging?

32. Gruenspecht and Lave indicate that extensive trading in rights has occurred only when the expansion of emission sources has been called for. See Schmalensee and Willig (1989, vol. 2, p. 1538). (The Hahn and Hester (1989) article in the Yale Journal on Regulation indicates the almost total lack of development of market mechanisms elsewhere in such rights.) 
I looked for both theoretical and applied work that would form a basis for evaluating the new policy instruments that have come onto the stage in the regulatory theater in the last few years. During the late 1970 s and early 1980s Congress was flooded with proposals for generic process for reducing excessive regulation. There were to be "zerobased" appraisals of agencies that would either renew the legislative mandate or abolish the agency on a time schedule. Other plans called for moving the agencies to the Executive Office with presidential (or congressional, or court) vetting authority over agencies' major decisions. These plans have not had the same public exposure in recent years. Is there theory in public regulation or accumulated experience with generic reform that can explain why these policies disappeared? There have been fairly widespread experiments at the state level and in the United Kingdom with "price caps" by which ceiling prices are set in the public utilities and then adjusted periodically by the difference between the inflation rate and a designated productivity growth rate. Are solutions to problems in managing rate base regulation in inflation consistent with interest group theory? The use of fines or charges for exceeding standards has been widely advocated and recently adopted in the 1990 Clean Air Act. Would charges and fines be more effective than equipment requirements or emissions limits in achieving the (whatever) goals of HSE regulation ? $^{33}$

Perhaps the search for positive theory for policy analysis is misguided and should be put aside in favor of focusing on the development of more effective regulatory agency procedures. This work is described in Baron's essay. Although impressive for its originality and rigor, it can scarcely be described as ready for implementation. There may be mistakes in judgment on what to abstract. The approach is to construct a highly abstract model of the firm, with an even more abstract model of government, but to add realistic depictions of the states of information and of the interaction patterns between firm and government. Further, it realistically depicts strategies for the regulator with less information than the regulated. But the model of the regulatory process is so limited

33. Gruenspecht and Lave discuss Weitzman's methodology for answering that question, but they make no references to the empirical work necessary to determine the critical elasticities of the supply and demand functions for "bad" reductions to be achieved more effectively by the use of fines or by emissions limits. 
that the resulting set of pricing rules cannot be tried in the agencies. Price is a two-part tariff. The first part is negative, and the second, the profit margin on sales, varies from zero to a monopoly level, depending on what the agency wants to do. Is the first part paid by the Treasury to the firm or by the agency in auctioning the license? This does not seem to meet Gruenspecht and Lave's basic condition for good policy, that the tariff have administrative simplicity and transparency, as well as the attributes of efficiency and equity.

What then makes the Handbook useful? The Noll, Brautigam, Joskow-Rose, and Gruenspecht-Lave chapters lead toward the development of theory of the goal-setting process. ${ }^{34}$ But currently there is not enough positive theory describing what allows congressional staff to develop arguments for priorities in deregulation. Nor can predictions be made about where markets will develop in place of regulation or about how well new policy instruments are likely to work. The specter of default confronts industrial organization - those making decisions in government and industry on policy will turn to the finance professors and the political scientists for expertise and advice.

Comment by Sam Peltzman: Alvin Klevorick identifies some important trends in the economic analysis of the firm and of government regulation. The megatrend that he identifies is increased sophistication. Firms are no longer treated merely as cost functions. They are understood to be a complex set of relationships among owners, managers, workers, and so forth. Regulation is not merely a constraint easily modeled as a dummy variable; it is now treated as the endogenous outcome of interactions among politicians, constituents, bureaucrats, and maybe a few others. The process, as well as the rules, matters. For this reason economists increasingly do interdisciplinary work with political scientists and lawyers, so increased sophistication has also bred more humility.

As Klevorick points out, little of this increased sophistication has filtered into empirical work. By way of contributing to a fuller understanding of the Handbook, I want to focus on the empirical literature

34. I found Noll's approach more promising than that of Gruenspecht and Lave, since they describe the goals of HSE regulation to be endogenous within the agency. They do not specify why then the legislature creates the agency. 
on regulation. Specifically, I will refer to two very good summaries in the Handbook, one by Noll and the other by Joskow and Rose. I want to use these summaries to indicate just what methods are in fact used by the leading empirical researchers in the field, at least those who merit inclusion in these two surveys. By method I mean the overall modeling strategy in the terms set out by Klevorick. That is, do they go beyond a setup with the profit-maximizing, cost-minimizing firm subject to or not subject to some exogenous deus ex machina called "regulation",?

By and large the answer to that question is no. There doesn't even seem to be, at least in my reading of these surveys, any significant movement toward a more sophisticated conceptualization. I will close by indicating why I think naiveté prevails in the empirical work and what some of its advantages might be.

I begin with Noll's survey of tests of interest-group theories of politics. He identifies two main strands in that empirical literature. Before about 1970, the tendency was to look at outcomes, of prices, profits, and so forth, in regulated markets. If these were arguably closer to a monopolistic than to a competitive equilibrium, that would lead to suspicion that interest groups were dominating the process. More recently, Noll says, researchers tend to look at politics. For example, do congressional representatives vote with the main interest groups in their constituencies? Do the regulatory agencies respond to the preferences of Congress and interest groups in specific cases?

Here, there clearly has been some increase in sophistication in that the political context in which interest groups and regulators function is given explicit recognition. But that shift in attention has more of the character of substituting one black box for another. In the earlier literature, "regulation'" was the black box on the right-hand side of the regression. The appropriate coefficient meant that regulation generated results favorable to interest groups. The newer literature puts variables such as roll call votes on energy policy on the left-hand side of a regression, and on the right-hand side it puts some measure of interest group strength such as how much coal or oil gets dug up in a state. When one gets to the empirical bottom line, neither the older approach nor the newer one pays much attention to process or complex interactions. That is not meant as criticism, it is just a fact.

Joskow and Rose survey the effects of regulation. This is a larger 
literature, although it overlaps the one that Noll reviewed. It is also more diverse. The primary question here is, What is the effect of regulation on $X$, where $X$ could be prices, profits, wage rates, innovation, and so forth? Joskow and Rose distinguish four techniques that have been used to answer this question, of which two dominate. I will limit myself to those two.

One of these is a comparison of regulated, as opposed to unregulated, firms. This can be done either cross-sectionally, or it can be done before and after some regulatory change. The other important approach is structural modeling or simulation of regulated firms or markets. This tends to be applied to cases in which all the firms or all the markets are subject to a similar kind of regulation. For example, one might ask, Is there overcapitalization in the utility industry? One way this question has been addressed is to estimate a production function, then combine estimates of marginal products and factor prices to deduce whether there is too much capital in the industry.

How is regulation treated in these studies? By and large, very naively. In the first approach - the comparison of regulated and nonregulated firms-regulation is typically a dummy variable in regression. In the second approach, some prior theoretical belief about the effect of regulation, for example, something like the Averch Johnson hypothesis, is applied directly. There is usually no attempt to cope with the actual complexity or variety of regulatory agency procedure.

How are firms or markets treated in this literature? Also, fairly naively. The firms are, by and large, profit-maximizing, cost-minimizing entities of the type that Klevorick tells us the theorists have long since passed by. This is especially important in the structural modeling, simulation branch of the literature that Rose and Joskow review. For example, if the question is, Is there overcapitalization? the answer comes from estimating a departure from cost minimization and attributing that to a regulatory constraint.

In reading this very good survey of the literature, I did not discern any broad tendency to move to more sophisticated conceptualizations of the problem. If there is a trend, it is toward more sophisticated technique; and that occurs in several dimensions. Possibly, there is a tendency toward more of the structural modeling and away from reduced-form, dummy-variable approaches. There is possibly a trend toward the simulation of more complete models and away from standard 
modes of regression analysis. For example, one might use some existing estimate of the relevant elasticities to calibrate a model of a market, and then subject that model to some regulatory shock.

Another trend, and this is common to all of the empirical industrial organization literature, is the use of financial-market data to summarize the effects of regulation in an effort to cut through some of the complexities. For example, one might ask a question, such as, Were the railroads forced to dissipate wealth via excess capacity when they were more regulated? One answer could be derived by modeling of the railroad-capacity decision. Another increasingly common approach is to examine the behavior of railroad-stock prices when, for example, events that increased the probability of deregulation occurred and then draw some inferences from the stock price behavior about what the effect of the regulation was on those railroads.

In summary, the broad picture is, we have an increasingly sophisticated theoretical understanding of the problem of regulation, coupled with more sophisticated measurement technique. But the basic conceptualization of the problem remains pretty much what it was twenty years ago.

One reason for this primitive conceptualization, I believe, has to do with how progress is currently being made in the empirical analysis of regulation. It is much more than we would like to believe via a steady accumulation of well-organized facts, rather than through straightforward hypothesis testing. Consider, as one example, the effect of regulation on wages, which is one of the subliteratures that Joskow and Rose summarize. There is no highly worked-out theory of the effect of regulation on wages, just some hunches guided by several theories. (Joskow and Rose list four hypotheses that might lead to an effect of regulation on wages.) In a case like this one, the tendency is to apply a variety of techniques to the problem. There are cross-sectional wage studies with a regulatory-dummy variable added. There are comparisons of pay for the same jobs in regulated firms and, say, nearby unregulated firms. There are time-series studies, sometimes combined with crosssectional data, which take advantage of the regulatory changes that have occurred, most prominently the deregulation of the late 1970s and early 1980s. Inevitably, this literature produced conflicting results, but an overall pattern emerged suggesting that, on average, workers benefited from regulation. 
To the extent that there is progress here, it comes from this steady, incremental accumulation of results, and the process would, I think, be impeded, rather than promoted, if researchers didn't have a common language. At least for the foreseeable future, that language needs to be fairly simple if one is going to find any intelligible patterns. A fair characterization of the way that this literature on the effect of regulation on wages treats regulation is that usually regulation is regulation. It is not a series of processes, each with its own peculiarities. Similarly, not too much attention is paid to the internal structure of firms or unions. Basically, firms are firms, unions are unions. Every firm and every union has pretty much the same goal as any other, to the extent that researchers even explicitly recognize goals as a problem.

If that common language had been dropped after the first few conflicting results, the fact-building process probably would have been impeded, or it might even have dissolved into separate lines of inquiry; for example, one might focus on the structure of unions and firms and another on the interactions of components of regulatory agencies, and so forth.

Progress does not, of course, require researchers to use the simplest common language. There is, sometimes, a gain to recognizing that firms are not firms or that regulatory agencies differ. But even at this level, it probably helps if the distinctions are easily incorporated into the work of successive researchers. Thus one might distinguish firms by some easily measured attribute such as their size or might distinguish regulation by some broad characterization of the mode of regulation.

At some point, perhaps, deeper subtleties may prove useful points of departure for empirical research, but I have a strong suspicion that this is not going to happen soon. I think that, for the foreseeable future, empirical research on regulation will continue to be an enterprise of building facts organized around a fairly simple theoretical superstructure, which is little affected by a recent advances in theory. This is not, of course, an altogether appealing prospect.

For example, consider the literature on the effects of airline regulation. This is a long literature and, as such things go, a deep one in the economics of regulation. It was initially conducted within a simple theoretical framework that yielded some very fruitful predictions about the effect of deregulation on prices and quality. But this simple framework also failed to predict other salient characteristics of the industry 
that emerged after deregulation. There were, for example, changes in the structure of prices and the firm-structure of the industry that could not have been predicted from that earlier, very simple, conceptualization of the airline market.

One would like to think that the missed results would be inspiring a lot of theoretical work on things like transportation networks or pricing strategies, which then feeds back to further empirical work. By and large, however, this is not happening. Instead, the empirical researchers tend to tweak the existing theory more or less as an excuse to get on with fact building. Progress in this field is likely to continue to be slow unless the hiatus between theoretical and empirical work is narrowed.

General Discussion: Several participants disagreed with Franklin Fisher's negative assessment of the state of theory in the industrial organization field. While Fisher had questioned the usefulness of theories that are only applicable in specific cases, Lawrence White said that there should be suspicions about any theories that apply to all cases. He claimed that in such a situation "we are dealing with a tautology, not with [a] theory." White noted that for such a practical application as antitrust work, universal theory was not necessary.

Steven Salop claimed that industrial organization theory has been very successful in telling stories to explain how various phenomena occur. He cited as examples the explanations for how firms compete in the presence of switching-costs, how information exchange affects the degree of competition, how price competition differs from quantity competition, and how firms can profitably deter entry.

Commenting on Fisher's advocacy of more industry studies, Mike Scherer quoted George Stigler's half-humorous observation that two such studies made in the same industry may yield widely varying conclusions when produced by two different parties. As an example, Scherer mentioned studies surrounding the IBM antitrust case. In two different studies, there was little similarity in the analysis, facts, or conclusions. Scherer suggested that getting good empirical information is part of the solution to this problem.

Martin Baily also noted the manner in which industrial organization (IO) theory has ignored empirical information. As an example, Baily said that there is convincing empirical evidence that the social return to research and development is higher than the private return. He claimed, 
however, that if one examines IO theoretical literature, one could conclude that "we have no idea whether [the] social return is higher than the private return, that we are just as likely to get competitive R\&D games that will mean that there is too much $R \& D$ as [ones that mean that] there is too little.",

In agreeing with Baily, Ralph Landau said that another problem with theoretical approaches in IO is that firms are treated in ways that do not reflect the real world. This fact, he said, has been exacerbated by dramatic changes in the world economy. He said that in order to compete against foreign firms in world markets, American firms must engage in practices that might once have been considered oligopolistic. While those practices might have once been viewed as having a negative effect on social welfare, today they might have positive welfare benefits for the country because of the manner in which competition has changed. Landau was concerned that IO theories had not taken changes in the nature of competition into account and that these theories would be used in antitrust law in a manner that would have negative consequences for the national economy.

Michael Whinston agreed with Fisher's claim that IO models may miss the richness of real-world situations. He said, however, that he felt that the field was moving in the right direction on this issue. As an example, he noted that while the Cournot model is incomplete in its applicability to many industries, developments such as the KrepsScheinkman model have shed light on how to relate the applicability of the model to actual industry conditions.

Michael Katz claimed that not as much progress has been made with respect to IO theory as some of the participants had argued. He said that while theories have undergone refinement over the past twenty years or so that might make their logic clearer, he doubted that there had been much progress made in the explanatory ability of theory. As an example, he said that while theories of information exchange may have improved our understanding of theories as theories, they have done little to improve our understanding of the way in which the world operates.

Several of the participants discussed the relationship between theory and empirical work in the field of industrial organization. Ariel Pakes disputed Franklin Fisher's assertion that empirical work has not kept pace with theory; he believed the situation to be exactly the opposite. 
As an example, Pakes said that if one examines plant data in a particular industry, one will be surprised about the heterogeneity of the plants and the extent to which relative productivity and relative size change over time. According to Pakes, while many empiricists have attempted to explain these phenomena, theoretical models have not been created to fit the data. Pakes claimed that "theoreticians have given me no structure to help to analyze the kind of issues that I want to analyze.",

Robert McGuckin said that from his work at the Census Bureau he has come to believe that many IO economists are not interested in a careful examination of the "facts." McGuckin claimed that while labor economists and general macroeconomists have been willing to come to the census and try to link the data with their theories, IO economists have been less enthusiastic about working with the census data.

Dennis Mueller said that while IO's analysis of markets had become idiosyncratic with its many special cases, with respect to the theory of the firm, there still exists in IO some "generalized-organizing principles." He suggested going to refined structure-performance models in market analysis.

Richard Gilbert claimed that the state of industrial organization could be improved by engaging in an examination of international experiences. As an example, he cited the issue of deregulation in the electric power industry. He noted that by looking at countries around the world, one will find many forms for the institutional organization of this industry. This information, he claimed, can be helpful in determining the optimal institutional form for the industry in the United States.

Ronald Braeutigam said that one problem with the Handbook of Industrial Organization was the publication lag. Many of the articles, he claims, were finished several years earlier. As a result, he said that analyses of the latest government policy instruments were absent from some of the Handbook and were therefore unable to influence government policy. He specifically mentioned policy in the area of price caps.

Janusz Ordover pointed out that IO has skirted some issues that should be of fundamental importance to the field. He had recently been in Eastern Europe and claimed that IO had little to offer governments there that are struggling to privatize firms or build market institutions. 
Instead, he said, privatization plans in Eastern Europe are being written by lawyers and macroeconomists.

\section{References}

Grossman, Sanford J., and Oliver D. Hart. 1986. "The Cost and Benefits of Ownership: A Theory of Vertical and Lateral Integration." Journal of Political Economy 94 (August):691-719.

Hahn, Robert W., and Gordon L. Hester. 1989. "Where Did All The Markets Go?' An Analysis of EPA's Emissions Trading Program.' Yale Journal on Regulation 6 (Winter):109-54.

$\rightarrow$ Joskow, Paul L. 1985. "Vertical Integration and Long-Term Contracts: The Case of Coal-burning Electric Generating Plants." Journal of Law, Economics, and Organization 1 (Spring):33-80.

- 1987. "Contract Duration and Relationship-Specific Investments: Empirical Evidence from Coal Markets." American Economic Review 77 (March):168-85.

1988. "Price Adjustment in Long-Term Contracts: The Case of Coal." Journal of Law and Economics 31 (April):47-83.

1990. "The Performance of Long-Term Contracts: Further Evidence from Coal Markets.' Rand Journal of Economics 21 (Summer):251-74.

Kahneman, Daniel, Paul Slovic, and Amos Tversky, eds. 1982. Judgment under Uncertainty: Heuristics and Biases. Cambridge University Press.

Noll, Roger G., and James E. Krier. 1990. "Some Implications of Cognitive Psychology for Risk Regulation.”' Journal of Legal Studies 19 (June):747-79.

Schmalensee, Richard, and Robert D. Willig, eds. 1989. The Handbook of Industrial Organization. 2 vols. Amsterdam and New York: North-Holland.

Schwartz, Alan. 1990. "Legal Contract Theories and Incomplete Contracts." Paper presented at the Nobel Symposium No. 77, Contracts: Determinants, Properties, and Implications. Stockholm (August).

Simon, Herbert A. 1957. Models of Man: Social and Rational. John Wiley \& Sons.

Stigler, George J. 1971. “The Theory of Economic Regulation.” Bell Journal of Economics and Management Science 2 (Spring):3-21.

Williamson, Oliver E. 1971. “The Vertical Integration of Production: Market 
Failure Considerations.' American Economic Review, Papers and Proceedings, 197061 (May):112-23.

1975. Markets and Hierarchies: Analysis and Antitrust Implications. Free Press.

1985. The Economic Institutions of Capitalism: Firms, Markets, Relational Contracting. Free Press. 